Document downloaded from:

http://hdl.handle.net/10251/63961

This paper must be cited as:

Holgado, JP.; Soriano Rodríguez, MD.; Jimenez-Jimenez, J.; Concepción Heydorn, P.; Jimenez-Lopez, A.; Caballero, A.; Rodriguez-Castellon, E.... (2010). Operando XAS and Raman study of the structure of supported vanadium oxide during the oxidation of $\mathrm{H} 2 \mathrm{~S}$ to sulphur. Catalysis Today. 155(3-4):296-301. doi:10.1016/j.cattod.2010.02.050.

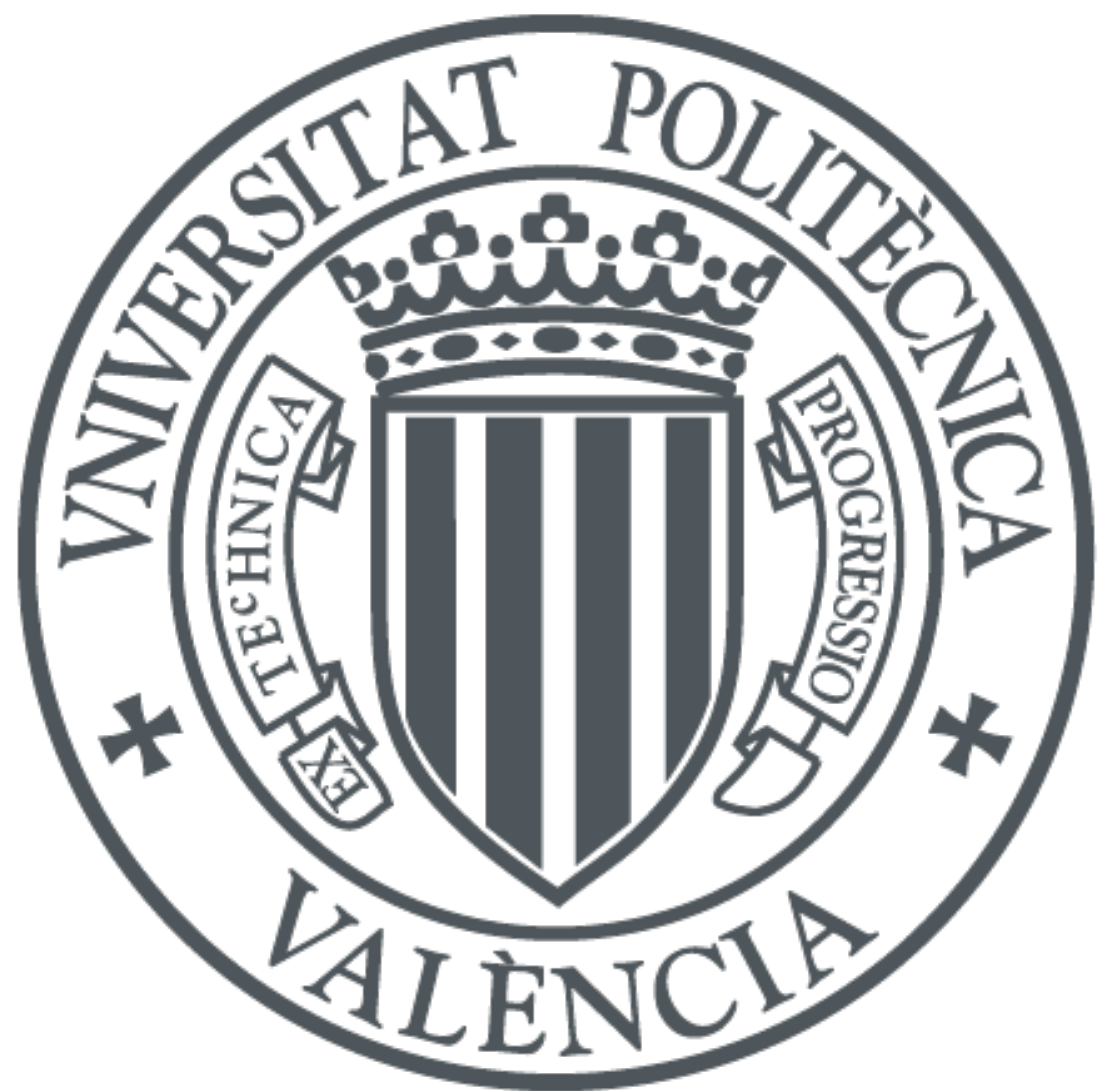

The final publication is available at

http://dx.doi.org/10.1016/j.cattod.2010.02.050

Copyright Elsevier

Additional Information 


\section{Operando XAS and Raman study on the structure of a supported vanadium oxide catalyst during the oxidation of $\mathrm{H}_{2} \mathrm{~S}$ to sulphur}

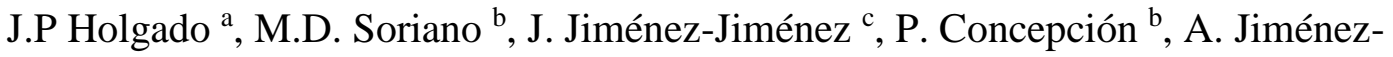
López ${ }^{\text {c }}$ A. Caballero a , E. Rodríguez-Castellón c , J.M. López Nieto ${ }^{\text {b,* }}$

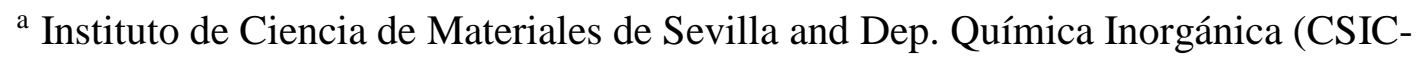
Universidad de Sevilla), Sevilla (Spain)

b Instituto de Tecnología Química, UPV-CSIC, Campus de la Universidad Politécnica de Valencia, Valencia (Spain).

` Dep. Química Inorgánica, Universidad de Málaga, Málaga (Spain)

* To whom correspondence: Fax: +34963877809; email: jmlopez@itq.upv.es 


\begin{abstract}
The modification of crystalline phases of a vanadium oxide supported on mesoporous zirconium phosphate during the partial oxidation of $\mathrm{H}_{2} \mathrm{~S}$ to sulphur has been studied by using an operando Raman-GC approach and XAS in reaction conditions. The catalyst, mainly presenting crystalline $\mathrm{V}_{2} \mathrm{O}_{5}$, is transformed during the oxidation of $\mathrm{H}_{2} \mathrm{~S}$ at $200^{\circ} \mathrm{C}$, presenting crystals of $\mathrm{V}_{4} \mathrm{O}_{9}$, which is identified by the presence of a band at ca. $900 \mathrm{~cm}^{-1}$ in the Raman spectra (using a $785 \mathrm{~nm}$ line of an Argon ion laser) and by the presence of a pre-edge at $5469.8 \mathrm{eV}$ (and a main-edge at $5482.2 \mathrm{eV}$ ) in XANES spectra. At the same time, it is observed a high conversion of $\mathrm{H}_{2} \mathrm{~S}$ to sulphur (the main reaction product) and $\mathrm{SO}_{2}$ (as minority). Both activity and selectivity depend on the time on stream. In this way, the selectivity to $\mathrm{SO}_{2}$ decreases from ca. 5 to $1 \%$ with the time on stream. This changes could be explained on the basis of the nature of V-species: the initial presence of $\mathrm{V}^{5+}-\mathrm{O}-\mathrm{V}^{5+}$ pairs and the appearance of $\mathrm{V}^{5+}-\mathrm{O}-\mathrm{V}^{4+}$ pairs at high time on stream.
\end{abstract}

Keyword: Operando, RAMAN, EXAFS, XANES, partial oxidation of hydrogen sulphide, vanadium oxides supported on mesoporous zirconium phosphate. 


\section{INTRODUCTION}

Supported vanadium oxide catalysts are interesting in a well number of reactions such as the partial oxidation of hydrocarbons or in the selective reduction of $\mathrm{NO}_{\mathrm{x}}[1-5]$. In addition to the oxidative dehydrogenation of short chain alkanes [4, 5], an important effort to study these catalytic systems in the partial oxidation of $\mathrm{H}_{2} \mathrm{~S}$ to elemental sulfur has been carried out in the last years [6-10]. At the moment, it is known that the characteristics of the metal oxide support and the nature of vanadium species strongly influence the catalytic performance and stability of supported vanadium catalysts during the partial oxidation of $\mathrm{H}_{2} \mathrm{~S}$ [6-10], although the catalysts could be modified during the reaction depending on the characteristics of catalysts and/or the reaction conditions. In this way, the reducing power of reactants seems to be an important factor in the partial oxidation of $\mathrm{H}_{2} \mathrm{~S}$ over $\mathrm{V}_{2} \mathrm{O}_{5}$ catalyst [11]. Thus, it has been reported that a reduced vanadium oxide, achieved by a reduction of $\mathrm{V}_{2} \mathrm{O}_{5}$ at $600{ }^{\circ} \mathrm{C}$ for 24 hours, showed a stable reactivity and an excellent conversion of $\mathrm{H}_{2} \mathrm{~S}$ and selectivity for the elemental sulfur. Recently we have observed how catalysts based in vanadium oxide supported on a mesoporous zirconium phosphate heterostructure change depending on the V-loading and the reaction conditions [12]. Accordingly, the nature of active and selective sites working during the reaction is still under discussion.

Raman studies have been carried out to determine the structure of vanadium oxide catalysts [13], while X-ray absorption spectroscopy (XAS) have been used to determine the oxidation state and coordination of vanadium-based catalysts [14]. More recently, they have been also used in operando conditions in order to clarify the nature of active and selective sites [15-17].

In the present paper we show for the first time an X-ray absorption spectroscopy (XAS) and Raman study, both working in operando conditions, on the selective 
oxidation of $\mathrm{H}_{2} \mathrm{~S}$ to sulfur using a vanadium oxide supported on a mesoporous zirconium phosphate heterostructure as catalyst. In addition, the reduction or reoxidation of catalyst after the catalytic test has been also studied.

\section{EXPERIMENTAL}

\subsection{Catalyst preparation}

A vanadium oxide supported on mesoporous zirconium phosphate (with 12 wt\% of $\mathrm{V}$-atoms, named as $12 \mathrm{VO}_{\mathrm{x}} / \mathrm{MZP}$ ) has been prepared by the wet-impregnation method of the mesoporous zirconium phosphate (MZP, $\mathrm{S}_{\mathrm{BET}}=556 \mathrm{~m}^{2} / \mathrm{g}$ ), using an aqueous solution of ammonium metavanadate. The mixture was rotaevaporated until complete dryness, dried overnight at $100^{\circ} \mathrm{C}$ and then calcined at $550^{\circ} \mathrm{C}$ for $6 \mathrm{~h}$. The resulting catalyst presents a surface area of $90 \mathrm{~m}^{2} \mathrm{~g}^{-1}$. The mesoporous zirconium phosphate heterostructure, MZP ( $\left.\mathrm{S}_{\mathrm{BET}}=556 \mathrm{~m}^{2} / \mathrm{g}\right)$, was prepared according to a previously reported preparation procedure [18].

For comparison, commercial $\mathrm{VOSO}_{4} .3 \mathrm{H}_{2} \mathrm{O}$ (Aldrich), $\mathrm{V}_{2} \mathrm{O}_{5}$ and $\mathrm{V}_{4} \mathrm{O}_{9}$ have been also used. $\mathrm{V}_{2} \mathrm{O}_{5}$ has been prepared from ammonium metavanadate by calcination in air at $550^{\circ} \mathrm{C}$ for $1 \mathrm{~h} . \quad \mathrm{A}_{4} \mathrm{O}_{9}$ sample has been prepared according to the preparation procedure previously described [19]. The sample shows an X-ray power diffraction

pattern with lines at $2 \theta=13.7,21.6,27.7,28.1,33.9,35.5,35.7,41.2,53.2,56.0^{\circ}$ in agreement to that previously reported for pure $\mathrm{V}_{4} \mathrm{O}_{9}$ [JCPDS-23-720].

\subsection{Catalyst Characterization}

The operando FT-Raman spectra were recorded with an “in via” Renishaw spectrometer, equipped with a microscope (Olympus). The samples were excited by the 785 nm line of an Argon ion laser (Spectra Physics Model 171) with a laser power of 
$2.5 \mathrm{~mW}$. Spectra were collected using a backscattering geometry with a $180^{\circ}$ angle between the illuminating and the collected radiation. A micro quartz reactor (i.d $6 \mathrm{~mm}$, length 200mm) located in a furnace has been used for in situ Raman studies. The furnace is provided with a small hole in order to allow focalization on the sample with the laser spot (spatial resolution of aprox $1.5 \mu \mathrm{m}$ ). The reactor was positioned below the microscope objective, working with a special long working distance objective of 50X (WD=10.6mm). The flow of the reactant has been controlled by mass flow controllers using a total flow of $65 \mathrm{ml} / \mathrm{min}$, with a $\mathrm{H}_{2} \mathrm{~S} /$ air/ $\mathrm{N}_{2}$ molar ratio of 1.2/5.0/93.8. The reaction has been performed on $50 \mathrm{mg}$ of catalysts powder at a reaction temperature of $200{ }^{\circ} \mathrm{C}$. Analysis of reactants and reaction products was carried out on-line using gas chromatography and two different chromatographic columns (Molecular Sieve 5A and Porapak T). The gas line after the reactor has been heated to $150{ }^{\circ} \mathrm{C}$ in order to avoid condensation of sulphur. Previous to venting the gases sulphur has been collected on a cold trap.

Vanadium K-edge X-ray absorption spectroscopy (XAS) measurements were performed at the beamline X10DA (superXAS) located at the Swiss Light Source (SLS), Villigen, Switzerland, using a Si (110) monochromator. The measurements were performed in transmission mode using ion chambers filled with $\mathrm{Ar} / \mathrm{N}_{2}$ as detectors. A modified commercial infrared (Specac) cell, equipped with Kapton windows was used for in operando measurements. Typically, $50 \mathrm{mg}$ of catalyst powder were pressed in a stainless steel sample holder in order to obtain self-supported discs of samples with appropriated transmission properties. Due to formation of sulphur in the reaction, heating of pipes after the cell is necessary, to avoid the condensation of this element. Collection of formed sulphur in the reaction will be done in a cold trap previous to vent the gases into the exhaust. Mass flow controllers were used for dosing the gases to the cell, using a total flow of $100 \mathrm{ml} / \mathrm{min}$, with $\mathrm{H}_{2} \mathrm{~S} / \mathrm{O}_{2} / \mathrm{He}$ molar ratio of $1 / 1 / 98$. For 
comparison, the spectra of catalyst before and after the catalytic tests have been also achieved at room temperature in helium. The XAS spectra were analyzed using the IFEFFIT programs package [20]. A factor of $\mathrm{k}^{2}$ was used for obtaining the Fourier Transforms (FT) of the EXAFS region of the spectra.

The catalytic tests were carried out in a fixed-bed tubular reactor at $200^{\circ} \mathrm{C}$ and atmospheric pressure, $50 \mathrm{mg}$ of catalyst and a $\mathrm{H}_{2} \mathrm{~S} /$ air/He mixture with a molar composition of 1.25/5.0/93.8 and a total flow of $130 \mathrm{ml} \mathrm{min}^{-1}$. The analysis of reactants and products has been carried out using the same procedure to that described previously for the operando Raman study.

\section{RESULTS AND DISCUSSION}

\subsection{Characterization of catalysts before and after catalytic tests.}

Fig. 1 shows the XRD patterns (Fig. 1A), and Raman (Fig. 1B) and XANES (Fig. 1C) spectra of supported-catalyst $\left(12 \mathrm{VO}_{\mathrm{x}} / \mathrm{MZP}\right.$ sample) before and after the catalytic test. For comparison, the corresponding spectra of the as-synthesized $\mathrm{V}_{4} \mathrm{O}_{9}$ are also included (Fig. 1, patterns $\mathrm{c}$ and spectra $\mathrm{f}$ and $\mathrm{i}$ ). We must indicate that the used supported-catalyst was recovered after a time-on-stream 300 min. During the catalytic test the $\mathrm{H}_{2} \mathrm{~S}$ conversion decreased from ca. 80 to $63 \%$, while the selectivity to elemental sulphur was higher than 99\%.

The XRD patterns of fresh catalysts shows the presence of $\mathrm{V}_{2} \mathrm{O}_{5}$ [JCPDS: 411426] and $\mathrm{ZrP}_{2} \mathrm{O}_{7}$ [JCPDS: 85-896]. When comparing to those achieved from used catalysts (Fig. 1A, pattern b) and pure $\mathrm{V}_{4} \mathrm{O}_{9}$ (Fig. 1A, pattern c), it can be concluded the disappearance of $\mathrm{V}_{2} \mathrm{O}_{5}$ and the formation of $\mathrm{V}_{4} \mathrm{O}_{9}$ [JCPDS: 23-720] after the catalytic tests [12]. 
On the other hand, fresh catalyst is characterized by the presence of bands at 998, 706, 530, 489, 410, 305, 289, 203 and $159 \mathrm{~cm}^{-1}$ in the Raman spectrum, which indicate the presence of crystalline $\mathrm{V}_{2} \mathrm{O}_{5}$ [13] (Fig. 1B, spectrum d). However the presence of isolated vanadium species on the surface of the support as minority cannot be ruled out. After the catalytic tests the Raman spectrum of catalyst changes (Fig. 1B, spectrum e). Thus, a band at $c a .900 \mathrm{~cm}^{-1}$ is observed in used catalysts, while the main features of the bands related to $\mathrm{V}_{2} \mathrm{O}_{5}$ crystallites are not observed. This spectrum is very similar to that achieved with the as-synthesized $\mathrm{V}_{4} \mathrm{O}_{9}$ (Fig. 1B, spectrum $\mathrm{f}$ ), which is also in agreement to one reported by Nilson et al. [21] during the study of the propane ammoxidation over $\mathrm{V}_{2} \mathrm{O}_{5}$ and one recently proposed from our group for this type of catalysts during the partial oxidation of $\mathrm{H}_{2} \mathrm{~S}$ [12].

We must indicate that the Raman band at ca. $900 \mathrm{~cm}^{-1}$ characteristic of $\mathrm{V}_{4} \mathrm{O}_{9}$ [20] is only observed when excited with radiation of $785 \mathrm{~nm}$ while not observed when using an excitation wavelength of $514 \mathrm{~nm}$ [22]. This effect, explained by resonance effects in reduced vanadium oxides, makes their characterisation possible by properly selecting the laser excitation wavelength. Similar resonant effects have already been observed by Mestl et al. [23, 24] in partially reduced molybdenum oxide.

Figure 1C shows the V K-edges XANES spectra of catalyst before (Fig. 1C, spectrum g) and after the catalytic test (Fig. 1C, spectrum h), as well as the spectrum achieved with the as-synthesized $\mathrm{V}_{4} \mathrm{O}_{9}$ (Fig. 1C, spectrum i). For comparison, the preedge features for the XANES spectra are shown in Table 1. According to previous XANES results of V-based compounds [14], it can be concluded that $\mathrm{V}_{2} \mathrm{O}_{5}$ is mainly present in fresh catalyst while $\mathrm{V}_{4} \mathrm{O}_{9}$ seems to be the main phase in the used catalyst. In this case, the $\mathrm{V}_{4} \mathrm{O}_{9}$ phase in the catalyst seems to be more amorphous than the massive oxide phase, according to the more attenuated oscillations observed by XAS. 


\subsection{Raman study on catalysts during the $\mathrm{H}_{2} \mathrm{~S}$ partial oxidation.}

Figure 2 shows operando Raman spectra and their on-line simultaneous catalytic results for sample $12 \mathrm{VO}_{\mathrm{x}} / \mathrm{MZP}$ during the selective oxidation of $\mathrm{H}_{2} \mathrm{~S}$ with time on stream, TOS, from 0 to $180 \mathrm{~min}$.

The Raman spectrum of the sample at $200^{\circ} \mathrm{C}$ in helium shows the same bands to that obtained for fresh catalyst (bands at 998, 706, 530, 489, 410, 305, 289, 203 and 159 $\mathrm{cm}^{-1}$ ) indicating the presence of bulk $\mathrm{V}_{2} \mathrm{O}_{5}$ (Fig. 2, spectrum b). However, after some minutes in contact with the reaction mixture, the bands related to $\mathrm{V}_{2} \mathrm{O}_{5}$ disappear appearing a band at ca. $900 \mathrm{~cm}^{-1}$ (Fig. 2, spectra c to j). The band at ca. $900 \mathrm{~cm}^{-1}$, observed during all the experiment (after 180 minutes of time on stream), was also observed during the characterization of the catalyst after a catalytic tests in a fixed bed reactor. Thus, and according to that previously indicated, the band at ca. $900 \mathrm{~cm}^{-1} \mathrm{can}$ tentatively be assigned to $\mathrm{V}_{4} \mathrm{O}_{9}$ [21]. In addition, we can also conclude that this nonstoichiometric vanadium oxide is formed during the partial oxidation of $\mathrm{H}_{2} \mathrm{~S}$ at $200^{\circ} \mathrm{C}$.

On the other hand, Figure 2 also shows the catalytic results obtained during the operando Raman-GC measurements. It can be seen that the conversion of $\mathrm{H}_{2} \mathrm{~S}$ decreases from 99 to $90 \%$ after $120 \mathrm{~min}$. In this way, we must indicate that a similar behavior is also observed when the catalytic tests were carried out in a fixed bed reactor.

In all cases, sulphur has been the main reaction product while $\mathrm{SO}_{2}$ was observed as minority. However, a small difference in the $\mathrm{S} / \mathrm{SO}_{2}$ ratio is also observed with the time on stream. Thus, an initial selectivity of ca. $8 \%$ was observed for $\mathrm{SO}_{2}$ although it decreases with time on stream until selectivity to $\mathrm{SO}_{2}$ lower than $1 \%$ at a TOS of 120 min. In an opposite trend, the initial selectivity to elemental sulphur of ca. $92 \%$ increases until 99\% after 120 min of time on stream. 


\subsection{XANES/EXAFS measurements during the $\mathrm{H}_{2} \underline{\mathrm{S}}$ partial oxidation.}

Figure 3 shows the XANES spectra of $12 \mathrm{VO}_{\mathrm{x}} / \mathrm{MZP}$ catalyst during the treatment at $200^{\circ} \mathrm{C}$, while Table 1 shows the pre-edge peak position, the main-edge position as well as the difference between main-edge and pre-edge peak position in fresh and used catalysts. For comparison, Figures 4 shows the XANES spectra of reference compounds, i.e. $\mathrm{V}_{2} \mathrm{O}_{5}$, during the partial oxidation of $\mathrm{H}_{2} \mathrm{~S}$.

In the case of $12 \mathrm{VOx} / \mathrm{MZP}$ catalyst, it can be seen that in a He steam at room temperature (r.t.) or $200^{\circ} \mathrm{C}$ the XANES spectra indicates the presence of bulk $\mathrm{V}_{2} \mathrm{O}_{5}$ (Figure 3, spectra $a$ and $b$, respectively), which is characterized by a pre-edge position at $5470.6 \mathrm{eV}$ and a main-edge peak at $5483.7 \mathrm{eV}$. However, the XANES spectra are clearly modified during the reaction at $200^{\circ} \mathrm{C}$, and completely different XANES spectra are observed after the first 30 minutes of time on stream. Thus, the pre-edge peak shifts from 5470.4 (Fig. 3, spectrum b) to $5469.9 \mathrm{eV}$ (Fig. 3, spectrum d). At the same time, the main-edge position shifts from 5483.2 (in helium at room temperature) to 5482.9 (in Helium at $200^{\circ} \mathrm{C}$ ) and finally to $5482.1 \mathrm{eV}$ (when obtained in reaction conditions after a time of stream of 120 min, Fig. 3, spectrum g). This final spectrum is quite similar to that of the $\mathrm{V}_{4} \mathrm{O}_{9}$ (Figure 1, spectrum $\mathrm{f}$ ) suggesting that a partial reduction of $\mathrm{V}(\mathrm{V})$ to V(IV) species has occurred during the reaction.

The XANES spectrum of pure $\mathrm{V}_{2} \mathrm{O}_{5}$ shows a similar behaviour during the treatment with a reaction mixture (Fig. 4). Thus, $\mathrm{V}_{2} \mathrm{O}_{5}$ is clearly modified when in reaction conditions in the same way than that observed in supported catalyst. At this point we must indicate that the XANES spectrum of pure $\mathrm{V}_{4} \mathrm{O}_{9}$ remains mainly unmodified (spectrum not shown), presenting a great stability of this mixed valence compound in reaction conditions. So, after about two hours of time on stream, the 
XANES of all three samples (catalyst and reference materials) are similar, with the preedge peak shifted to about $5469 \mathrm{eV}$, with the main edge located at $5481 \mathrm{eV}$. The fact that in all cases the final spectra are quite similar to that of the $\mathrm{V}_{4} \mathrm{O}_{9}$ shows that a partial reduction of $\mathrm{V}(\mathrm{V})$ to $\mathrm{V}(\mathrm{IV})$ species occurs in reaction conditions. These results are in agreement to the Raman spectrum achieved in the same conditions.

These assertions are fully confirmed by the results obtained by Fourier Transforming the EXAFS region of the XAS spectra. Figure 5 shows the Fourier Transforms (FTs) obtained from the EXAFS spectra of the sample during the He treatment at $200{ }^{\circ} \mathrm{C}$ and after 2 hours of reaction. For comparison Figure 6 shows the EXAFS spectra achieved with $\mathrm{V}_{2} \mathrm{O}_{5}$ (Fig. 6A) and $\mathrm{V}_{4} \mathrm{O}_{9}$ (Fig. 6B) after the same treatments. Due to the high complexity of the vanadium oxides coordination shells, with four different V-O shells between 1.60 and 1.91A, and three V-V distances at 3.153.65 A, no fitting procedure of the signals have been accomplished. However, a direct comparison with the FT of the vanadium oxides references allows us to establish that in all cases, the FTs after reaction are similar to the $\mathrm{V}_{4} \mathrm{O}_{9}$ reference, with two peaks centered at about 1.25 and $1.95 \AA$, respectively. The fact that the peaks in the supported catalyst are wider than in the vanadium oxides references is related to a more heterogeneous and disordered state of the supported phases, an effect frequently observed in many supported catalytic systems [25]. This finding totally confirms the previous conclusion from the XANES spectra that the bulk $\mathrm{V}_{2} \mathrm{O}_{5}$, originally presents in the catalysts, and even the $\mathrm{V}_{2} \mathrm{O}_{5}$ reference, are partially reduced to a $\mathrm{V}_{4} \mathrm{O}_{9}$-like phase, which remains stable all along the catalytic reaction (Fig. 6B).

\section{$\underline{\text { General remarks }}$}

It is known that the catalytic performance of supported vanadia catalysts strongly depends on the supports and the V-loading, which determine the nature of V- 
species [12]. In this way, it has been reported that catalysts presenting $\mathrm{V}_{2} \mathrm{O}_{5}$ crystallites are more active and present lower catalyst decay than catalysts presenting isolated vanadium species on the surface of the support. For this reason, the catalytic behavior of our catalyst can be related to the presence of $\mathrm{V}_{2} \mathrm{O}_{5}$ crystallites, although the contribution of surface vanadium species cannot be completely ruled out.

The Raman and XAS results of our catalysts before and after the catalytic tests show the transformation of catalyst by changing the nature of crystalline phases in fresh $\left(\mathrm{V}_{2} \mathrm{O}_{5}\right)$ and in used $\left(\mathrm{V}_{4} \mathrm{O}_{9}\right)$ catalyst. Thus, one could propose the formation of a partially reduced V-compound during the catalytic tests as a consequence of the catalyst reduction. However, the extension of the partial reduction of $\mathrm{V}_{2} \mathrm{O}_{5}$ crystallites cannot be directly determined by the characterization of used catalysts since this could be also reoxidized during the characterization step.

In this way, we must remember that $\mathrm{VO}_{2}$ or $\mathrm{V}_{2} \mathrm{O}_{3}$ have been proposed as the final crystalline phase formed during the oxidation of $\mathrm{H}_{2} \mathrm{~S}$ at $235^{\circ} \mathrm{C}$ or $335^{\circ} \mathrm{C}$ over pure $\mathrm{V}_{2} \mathrm{O}_{5}$ or $\mathrm{V} / \mathrm{SiO}_{2}$ catalysts [6]. However, they are not observed in our case. For this reason, we considered that a study on the catalyst modification during the reaction should be performed more effectively by using the same characterization techniques in operando condition.

The characterization results carried out by Raman and EXAFS-XANES in operando conditions confirm that $\mathrm{V}_{4} \mathrm{O}_{9}$ is mainly formed during the reaction and it remains in the catalyst after the catalytic tests. At this point we must indicate that $\mathrm{V}_{4} \mathrm{O}_{9}$ can be easily formed by treating $\mathrm{V}_{2} \mathrm{O}_{5}$ with sulphur [26], and it is an intermediate product during the preparation of vanadium nitrides [27]. In fact, by the temperatureprogrammed reaction of $\mathrm{V}_{2} \mathrm{O}_{5}$ with $\mathrm{NH}_{3}$ the following sequence has been proposed: $\mathrm{V}_{2} \mathrm{O}_{5} \rightarrow \mathrm{V}_{4} \mathrm{O}_{9} \rightarrow \mathrm{VO}_{2} \rightarrow \mathrm{V}_{2} \mathrm{O}_{3} \rightarrow \mathrm{VO}_{0.9}$, last being transformed by the topotactic substitution of nitrogen for oxygen. 
It has been proposed that the selective oxidation of $\mathrm{H}_{2} \mathrm{~S}$ is carried out by a redox mechanism involving lattice oxygen [6-10]. Our results suggest that the catalyst reoxidation could be the determining-reaction step, favoring a partial reduction of the catalyst. However, $\mathrm{V}^{5+}-\mathrm{O}-\mathrm{V}^{4+}$ pairs can be proposed as the active and selective sites in steady-state conditions since a high selectivity to elemental sulfur is achieved over partially reduced catalysts (i.e. $\mathrm{V}_{4} \mathrm{O}_{9}$ with $\mathrm{V}^{5+}-\mathrm{O}-\mathrm{V}^{4+}$ pairs) instead of over total oxidized catalyst (i.e. $\mathrm{V}_{2} \mathrm{O}_{5}$ with $\mathrm{V}^{5+}-\mathrm{O}-\mathrm{V}^{5+}$ pairs).

On the other hand, the different oxidation state observed in our catalyst, but also in $\mathrm{V}_{2} \mathrm{O}_{5}$ after the reaction, with respect to that proposed by Shin et al. [6] can be explained by the different reaction conditions used in each case. Thus, Shin et al. observed $\mathrm{VO}_{2}$ and $\mathrm{VO}_{3}$ when the reaction is carried out at $325^{\circ} \mathrm{C}$ and a $\mathrm{H}_{2} \mathrm{~S} / \mathrm{O}_{2}$ ratio of ca. 2 in the presence of $\mathrm{NH}_{3}$ and steam and a time of stream of 20h [6]. It is clear that in the last conditions a higher reduction should be achieved. In this way, it has been proposed that the catalytic performance of V-based catalysts strongly depends on the redactor character of the reaction mixture [11], the reducing power of reactants being the most important factor in the selective oxidation of $\mathrm{H}_{2} \mathrm{~S}$. For this reason, it is evident that the nature of crystalline phases in the catalyst could be changed when using reaction mixtures with a high reductor character and/or when working at different reaction temperature. However, in the reaction conditions studied here, the catalysts achieved a steady-state condition when forming the partially reduced phase.

\section{Conclusions}

In this paper we have studied the modification of a V-based catalyst (a vanadium oxide supported on a mesoporous zirconium phosphate, $12 \mathrm{wt} \%$ of $\mathrm{V}$-atoms) during the selective oxidation of $\mathrm{H}_{2} \mathrm{~S}$ to sulphur by operando Raman and EXAFS-XANES. These results have been compared with those carried out with an used catalysts. In addition, 
and for a better understanding, we have also follow the modification of pure $\mathrm{V}_{2} \mathrm{O}_{5}$ and $\mathrm{V}_{4} \mathrm{O}_{9}$ during the catalytic test.

According to the results presented here bulk $\mathrm{V}_{2} \mathrm{O}_{5}$ which is mainly observed in the fresh supported catalysts, is clearly transformed into a like- $\mathrm{V}_{4} \mathrm{O}_{9}$ phase during the partial oxidation of hydrogen sulphide to sulphur at $200^{\circ} \mathrm{C}$, confirming previous results obtained during the characterisation of used catalysts [12]. This like- $\mathrm{V}_{4} \mathrm{O}_{9}$ phase is characterized by the presence of a band at ca. $900 \mathrm{~cm}^{-1}$ in the Raman spectrum (achieved with $785 \mathrm{~nm}$ line of an Argon ion laser) and a pre-edge peak at $5469.9 \mathrm{eV}$ and a main-edge at $5482.1 \mathrm{eV}$ in the XANES spectrum (achieved in vanadium K-edge X-ray absorption spectroscopy).

On the other hand, this like- $\mathrm{V}_{4} \mathrm{O}_{9}$ phase is also observed when the operando XAS study is carried out by using pure $\mathrm{V}_{2} \mathrm{O}_{5}$ as catalyst. However, no changes were observed in the nature of the catalyst when pure $\mathrm{V}_{4} \mathrm{O}_{9}$ was used as catalyst. These results are in good agreement to those achieved during the characterization of an used catalyst confirming a partial reduction of catalyst during the catalytic test for the partial oxidation of hydrogen sulphide to sulfur.

This conclusion is quite different to those previously proposed over $\mathrm{V}_{2} \mathrm{O}_{5}$ and $\mathrm{SiO}_{2}$-supported vanadium catalysts, suggesting that the reaction conditions, i.e the reduction power of the fed and/or the reaction temperature, are a key element in the transformation of the active phase.

Finally, it is also observed that the selectivity to sulphur increases when increasing the formation of $\mathrm{V}_{4} \mathrm{O}_{9}$ in the catalyst. May be, the presence of $\mathrm{V}^{5+}-\mathrm{O}-\mathrm{V}^{4+}$ pairs (as proposed in $\mathrm{V}_{4} \mathrm{O}_{9}$ ) instead of $\mathrm{V}^{5+}-\mathrm{O}-\mathrm{V}^{5+}$ pairs (as proposed in $\mathrm{V}_{2} \mathrm{O}_{5}$ ) favors a higher selectivity to partial oxidation products (i.e sulfur). In this sense, the formation of 
more oxidized products (i.e $\mathrm{SO}_{2}$ ) in addition to sulfur seems to be more favored in oxidized catalysts but decay with the time of stream in catalytic tests.

\section{Acknowledgments}

The authors gratefully acknowledge financial support from CICYT, Spain (NAN2000409267-C03-01 and NAN2004-09267-C03-02). We also thank Swiss Light Source (SLS) at the Paul Scherrer Institut (Proposal 20081090).

\section{$\underline{\text { References }}$}

1) J.M. López Nieto, Top. Catal. 41 (2006) 3.

2) J. N.J. van Lingen, O.L.J. Gijzeman, B.M. Weckhuysen and J.H. van Lenthe, J. Catal., 239 (2006) 34.

3) I.E. Wachs and B.M. Weckhuysen, Appl. Catal. A 157 (1997) 67.

4) T. Blasco and J.M. López Nieto, Appl. Catal. A 157 (1997) 117.

5) F. Cavani and N. Ballarini, A. Cericola, Catal. Today 127 (2007) 113.

6) M.Y. Shin, Ch.M. Nam, D.W. Park and J.Sh. Chung, Appl. Catal. A 211 (2001) 213-225.

7) M.Y. Shin, D.W. Park and J.S. Chung, Appl. Catal. B 30 (2001) 409.

8) M.W. Song, M. Kang and K.L. Kim, React. Kinet. Catal. Lett. 78 (2003) 365.

9) M.I. Kim, W.D. Ju, K.H. Kim, D.W. Park and S.S. Hong, Stud. Surf. Sci. Catal. 159 (2006) 225.

10) K.V. Bineesh, D.R. Cho, S.Y. Kim, B.R. Jermy and D.W. Park, Catal. Commun. 9 (2008) 2040.

11) J.D. Lee, N.K. Park, S.O. Ryu and T.J. Lee, Appl. Chem. 8 (2004) 601. 
12) M.D. Soriano, J. Jiménez-Jiménez, P. Concepción, A. Jiménez-López, E. Rodríguez-Castellón and J.M. López Nieto, Appl. Catal. B. 92 (2009) 271.

13) B.M. Weckhuysen, J.-M. Jehng and I.E. Wach, J. Phys. Chem. B 104 (2000) 7382.

14) G. Silversmit, J.A. van Bokhoven, H. Poelman, A.M.J. van der Eerden, G.B. Marin, M.F. Rayniers and R. De Gryse, Appl. Catal. A 285 (2005) 151.

15) G. Mul, M.A. Bañares, G. Garcia Cortez, B. van der Linden, S.J. Khatib and J.A. Moullijn. Phys. Chem. Chem. Phys. 5 (2003) 4378.

16) A. Bruckman, Chem. Commun. (2005) 1761.

17) S.T. Tinnemans, J.G. Mesu, K. Kervinen, T. Visser, T.A. Nijhuis, A.M. Beale, D.E. Keller, A.M.J. van der Eerden and B.M. Weckhuysen, Catal. Today, 113 (2006) 3.

18) J. Jiménez-Jiménez, M. Rubio-Alonso, D. Eliche-Quesada, E. Rodríguez-Castellón and A. Jiménez-López, J. Mater. Chem. 15 (2005) 3466-3472.

19) T. Miyake, T. Doi, Appl. Catal. A 131 (1995) 43.

20) M.Newville, J.Synchrotron Rad. 8 (2001) 322.

21) R. Nilsson, T. Limblad and A. Andersson, J. Catal. 148 (1994) 501.

22) Y. Zang, M. Meisel, A. Martin, B. Lücke, K. Witke and K.-W. Brzeinka, Chem. Mater. 9 (1997) 1086.

23) G. Mestl, J. Raman Spectrosc. 33 (2002) 333.

24) M. Dieterle, G. Weinberg and G. Mestl., Phys. Chem. Chem. Phys. 4 (2002) 812.

25) D. C. Koningeberger and R. Prins, X-Ray Absorption: Principles, Applications, Techniques of EXAFS, SEXAFS and XANES; Wiley: New York, 1988.

26) G. Grymonprez, L. Fiermans amd J. Vennik, Acta Cryst. A 33 (1977) 834.

27) H. Kwon, S. Choi and L. T. Thompson, J. Catal. 184 (1999) 236. 


\section{Caption to Figures}

Fig. 1. XRD (A), Raman (B) and XANES (C) results of fresh ( $a, d$ and $g$ ) and used ( $b$, $e$ and $h)$ supported vanadium oxide catalyst $\left(12 \mathrm{VO}_{\mathrm{x}} / \mathrm{MZP}\right)$. For comparison, the corresponding spectra of the as-synthesized $\mathrm{V}_{4} \mathrm{O}_{9}$ are also included ( $c, f$ and $i$ ). Symbols: $\mathrm{V}_{2} \mathrm{O}_{5}(\boldsymbol{\square})$; $\mathrm{ZrP}_{2} \mathrm{O}_{7}(\circ)$; $\mathrm{V}_{4} \mathrm{O}_{9}(\boldsymbol{\Delta})$; elemental sulfur ( $\square$ ).

Fig. 2. Operando Raman spectra (left) of $12 \mathrm{VO}_{\mathrm{x}} / \mathrm{MZP}$ catalyst during partial oxidation of $\mathrm{H}_{2} \mathrm{~S}$ and the corresponding catalytic results, i.e. $\mathrm{H}_{2} \mathrm{~S}$ conversion ( $\boldsymbol{\bullet}$ ) and selectivity to elemental sulphur ( $\square$ ) (right). Spectra: a) at r.t. in $\mathrm{He}$; b) at $200^{\circ} \mathrm{C}$ in $\mathrm{He}$; c) during reaction at a TOS of $15 \mathrm{~min}$; d) during reaction at a TOS of $30 \mathrm{~min}$; e) during reaction at a TOS of $45 \mathrm{~min}$; f) during reaction at a TOS of $60 \mathrm{~min}$; g) during reaction at a TOS of $75 \mathrm{~min}$; h) during reaction at a TOS of $90 \mathrm{~min}$; i) during reaction at a TOS of $120 \mathrm{~min}$; j) during reaction at a TOS of $180 \mathrm{~min}$. Reaction conditions: $50 \mathrm{mg}$ of catalyst, total

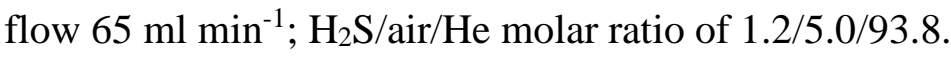

Fig. 3. Normalized absorption spectra (XANES) for the $12 \mathrm{VO}_{\mathrm{x}} / \mathrm{MZP}$ catalyst at different time on stream (A). For comparison, the enlarged pre-edge region of V-O bond is also included (B). Spectra: at room temperature in $\mathrm{He}(\mathrm{a})$; at $200^{\circ} \mathrm{C}$ in $\mathrm{He}(\mathrm{b})$; spectra in reactions conditions at a TOS (in min) of 15 (c), 30 (d), 45 (e), 60 (f), 75 (g), 90 (h), 120 (i).

Fig. 4. . Normalized absorption spectra (XANES) for the $\mathrm{V}_{2} \mathrm{O}_{5}$ catalyst at different time on stream (A). For comparison, the enlarged pre-edge region of $\mathrm{V}-\mathrm{O}$ bond is also included (B). Spectra: at $200^{\circ} \mathrm{C}$ in He (a); spectra in reactions conditions at a TOS (in min) of 15 (b), 30 (c), 45 (d), 60 (e), 75 (f), 90 (g). 
Fig. 5. Fourier transforms of the EXAFS region obtained for the 12VOx/MZP catalyst before (dashed line) and after a treatment in reaction conditions at a TOS of $120 \mathrm{~min}$ (solid line). Reaction conditions as in Fig. 3.

Fig. 6. Fourier transforms of the EXAFS region obtained for the $\mathrm{V}_{2} \mathrm{O}_{5}(\mathrm{~A})$ and $\mathrm{V}_{4} \mathrm{O}_{9}(\mathrm{~B})$ catalyst before (dashed line) and after a treatment in reaction conditions at a TOS of 120 min (solid line). Reaction conditions as in Fig. 3. 
Table 1. Pre-edge and main peak observed in XANES spectra of $12 \mathrm{VO}_{\mathrm{x}} / \mathrm{MZP}$ catalysts and references.

\begin{tabular}{lllll}
\hline Sample & Treatment $^{1}$ & pre-edge peak & Main-edge & $\Delta(\mathbf{e V})^{2}$ \\
& & position (eV) & position (eV) & \\
\hline $\mathrm{V}_{2} \mathrm{O}_{5}$ & $\mathrm{He} / \mathrm{rt}$ & 5470.6 & 5483.7 & 13.1 \\
$\mathrm{~V}_{4} \mathrm{O}_{9}$ & $\mathrm{He} / \mathrm{rt}$ & 5469.8 & 5482.2 & 12.4 \\
$\mathrm{VOSO}_{4}$ & $\mathrm{He} / \mathrm{rt}$ & 5469.8 & 5480.1 & 10.3 \\
\hline $12 \mathrm{VO}_{\mathrm{x}} / \mathrm{MZP}$ & $\mathrm{He} / \mathrm{rt}$ & 5470.4 & 5483.2 & 12.8 \\
$12 \mathrm{VO}_{\mathrm{x}} / \mathrm{MZP}$ & $\mathrm{He} / 200^{\circ} \mathrm{C}$ & 5470.4 & 5482.9 & 12.5 \\
$12 \mathrm{VO}_{\mathrm{x}} / \mathrm{MZP}$ & $\mathrm{RC}$, after a TOS of 120 & 5469.9 & 5482.1 & 12.2 \\
& min & & & \\
\hline
\end{tabular}

1) Treatment of samples: in Helium at room temperature (rt) or at $200^{\circ} \mathrm{C}$; in reaction conditions (RC) as in Figure 2.

2) Difference between main-edge position and pre-edge peak position. 